\title{
Shamanic Rites Seen from a Shamanic Perspective
}

\section{Prologue}

Since the last half of the nineteenth century social scientists have been investigating the shamanic rite. In most cases, these studies have been concentrating on the form of the rite. This paper investigates the content of the shamanic rite, contrasting it to the form, and uses the shaman's point of view as the orientation of the analysis.

My active interest in shamanism started some nineteen years ago during my last year at university. At that point, I came to the conclusion that shamans, basically, were stone-age psychotherapists, and that they came to this position because the various societies in which shamanism was practiced realized that sensitive people could be a benefit to the group. Rather than pushing them out, keeping them alienated, and possibly draining power from the group, they were trained to help others in a variety of ways.

Although this was my stated conclusion, I privately felt that there was something more to the shaman's way than was expounded by the ethnographers, psychological anthropologists, historians of religion, and missionaries whose works I had read while doing my research. I was fascinated by what the shamans of old told about their work, yet being trained to think rationally in the social sciences, I did have a hard time in understanding what they were saying, and this was because I could not accept what they were saying as being possible. It was something akin to reading poetry, imperfectly translated from an ancient, exotic language which I could never hope to learn.

Still, I did get beyond the barrier of thinking of shamans as schizophrenics, or, worse, charlatans who used the placebo effect on psychosomatically ill patients by telling holy lies. It was clear that something actually was 
happening, cures were being effected, which we, in our society, would call unusual coincidences or small miracles. These were being realized, and the scientific investigators from the outside world had no way to explain them. And I was no different. I had no way of explaining them either. It was a mystery. Or, perhaps as certain native Americans say (in translation), the Great Mystery.

\section{Definitions}

While I realize that the debate over the definition of what a shaman is will continue through the years, for the purpose of this paper I define a shaman as follows: a shaman is someone who changes his or her state of consciousness at will, in order to journey to another reality, a "nonordinary reality," the world of the spirits. There she meets with her spirit helpers to ask for help, power, or knowledge for herself and/or others. Mission accomplished, the shaman journeys back to ordinary reality where he uses or dispenses the newly gained knowledge and/or power (cf. Eliade 1964; Harner 1980). I do not consider shamanism, in itself, to be a religion, though it often can be a part of a religion. It should be noted, however, that the practice of shamanism often gives what are loosely termed "religious experiences," as well as providing a set of values and practices which the shaman lives by.

I define the shamanic rite as any action or series of actions made by the shaman with the definite purpose of bringing the power of non-ordinary reality to ordinary reality. It is the bridge the shaman builds between our world and the world of the spirits. The ritual is not the source of power, but the vehicle for bringing the power to the recipient(s). It is the means, not the goal. In other words, that which is really going on in the shamanic rite is going on in non-ordinary reality. The ritual is the form. The power and spirit are the content.

To do shamanic work it is absolutely essential to have access to the experience of the reality of non-ordinary reality. Almost everyone has experienced non-ordinary reality, for example as dreams or near death experiences, but in our society, because of the reluctance to accept nonordinary reality as a reality, the majority of people suppress these experiences in one way or another, for fear of what others may think. Fortunately, this is changing and people are now more open to investigating their experiences and even talking about them (Moody 1977). 
It is important to try to describe this other reality, as this is the reality that the shaman is operating in when she or he is shamanizing. Anthropologist Michael Harner points out:

All the phenomena that characterize the so-called material world will appear just as real and material there [in non-ordinary reality] as they do here .... But the shaman does not view these non-ordinary phenomena as mental in the sense that they are regarded as a projection of one's own mind. Rather, the mind is being used in order to gain access, to pass through a door into another reality which exists independently of that mind. (Harner and Doore 1987: 4) (italics added)

The Mazatec shaman Maria Sabina describes non-ordinary reality as:

... a world beyond ours, a world that is faraway, nearby, and invisible. And there it is where God lives, where the dead live, the spirits and the saints, a world where everything has already happened and everything is known. (Wasson et al. 1974: 17)

However, not everyone's experiences of non-ordinary reality are as Maria Sabina describes them, but instead are glimpses or moments when nonordinary reality breaks through the barriers into ordinary reality. In our culture, these breakthroughs are referred to variously, depending on how they are viewed, as "psychotic episodes" on the one extreme, to "miracles" and "revelations" on the other, with "unexplainable events" being a more neutral nomenclature, or even dismissed as "imagination" or "fantasy." But in order to shamanize, the shaman must know non-or dinary reality for the reality that it is.

\section{Background}

In recent years, much of the research on shamanism has been done in the library. This is partly due to the historical fact that the State has never been fond of the shaman, and the number of observable traditional shamans has decreased even faster than the alarming disappearance of their cultures and habitats. Be that as it may, some of the analyses produced have been rich in information, and have shown insight. While it is admirable that such feats of intellectual competence can be performed, a fact which speaks highly of the fieldwork done by preceding generations of anthropologists, missionaries, and other students of religion and humanity, one must also remember that those students had their own criteria, and 
their own prejudices and blind spots, which are not always clear or easily understandable when one is away from the actual setting in time and space. These weaknesses can be, and often are, amplified the farther one gets from the actual source. As a result, there has often been a lack of deeper understanding of what actually is taking place in the shamanic ritual. I feel that this is due to the fact that generally the point of view of the academic observer is outside the action.

The literature on shamanism is filled with examples where the writer was a particip ant - but only in his or her role as observer - of a shamanic ritual. Observer participation has been one of the main information gathering methods in the social sciences since the beginning. But a part of this method has also been the maintainence of academic distance. While it is almost impossible to maintain this distance one hundred percent in the actual field situation, due to practical considerations alone, academic distance is easily enough maintained in the field reports and monographs. However, the practice of academic distance in itself makes it impossible to fully understand, let alone explain, what is going on in the shamanic séance. To accomplish this, one must go beyond merely accepting the shaman's point of view as valid. To fully grasp what is going on it is also necessary to be aware of the presence of power, which, in part, comes from the spirit essence found in everything. This, which for our culture is the concept we call animism, is an established reality for the shaman, and during the shamanic rite the shaman taps the spirit power of the objects which surround him, in many cases objects which he has selected, his paraphernalia, not because they symbolize certain powers (Hoppal 1987), but because they contain those powers, and in some cases are those powers. As anthropologist Don Handelman (1972) very insightfully observes:

The paraphernalia of the shaman were also termed 'power' ... Properly consecrated they were considered to be physical extensions of the shaman's spirit-helper. As such, they were always in contact with the spirit-helper .... (1972: 92)

But the spirit power in the shamanic rite is not limited to the shaman's trappings. Even more important is the spirit power the shaman calls to the séance to do the work, as well as the spirit power he brings back from the spirit world to help the person he is working for. If, then, one is not aware of the presence of power during a shamanic rite, the most one can hope for is either an empirical description of events, or an analysis at some theoretical level, but still an analysis based on speculations. This is 
what most attempts to understand the shamanic rite are, as most outside observers have not observed the power, or neglected to write about it for one reason or another. I have chosen one example of each to illustrate my point.

\section{Descriptive Observation}

A good, and unusual, example of an empirical description is Ivan A. Lopatin's A Shamanistic Performance to Regain the Favor of the Spirit (1940-41). Although this is what I would call a very sympathetic presentation of a shamanic séance, Lopatin's choice of the word "performance" does indicate something - perhaps unconscious - about his view of the shaman's work. The concept of performance itself puts a filter between the observer and the shaman. In many reports the shamanic rite is referred to as a "performance," and this choice of wording, as well as "audience" and "role," emphasizes the form, and indicates the bias on the part of the observer. This could be at least partly responsible for later misunderstandings.

The most unusual thing about Lopatin's description is that it exists. As Lopatin indicates, he was extremely fortunate in witnessing this ritual for several reasons, one of them being the very intimate character of the ritual itself. It was not a ritual to regain power for a second party, but to regain power for the shaman herself. Nor was it a public ritual witnessed by the rest of the clan. The only other human witnesses were an interpreter, a female relative of the shaman, two children who were put to bed (but were probably peeking from under the covers), and a cousin of the shaman who assisted her. Because of the extremely intimate nature of this rite - the shaman begging the return of her spirit-helper's aid and for giveness after a tragedy for which she felt at least partly responsible - it is surprising that there were any witnesses at all. In most cases, this is the kind of shamanic ritual which would be done by the shaman alone with the spirits.

Lopatin then goes on to describe the ritual, the preparations, the lengthy, moving invocations accompanied by dancing, the offering of food and drink to the shaman's spirit-helper, and the closing dance.

I chose this account because of the openness of its intimacy, and also because of the very human way Lopatin reported it. However, in his reporting, Lopatin makes it clear that he is not participating, but observing, counting how many times the assistant dances around the fire, 
and so on. I also chose this account because it does deal with what could be considered the central issue of shamanism: the importance of the shaman's relationship to her spirit helpers. "Without thee I am only a poor woman. With thy assistance I am powerful"' (1940-41: 354), she cries, showing that it is the spirits who do the actual work.

\section{Theoretical Speculation}

An outstanding example of a speculative analysis is contained in AnnaLeena Siikala's monumental work, The Rite Technique of the Siberian Shaman (1978). She has based her analysis on Lauri Honko's ideas expressed in his Role-taking of the Shaman (1969). As a result, her analysis is limited, and some of the statements which form the theoretical foundation are simply incorrect. For example, she writes:

The shamanizing séance, the ritual performance embodying the shaman's public activity, is the key to understanding the whole ideology behind shamanism. (Siikala 1978: 28. Italics added)

In fact, "the key to understanding the whole ideology behind shamanism" is the ability to understand the shaman's relationship to his spirit helpers and teachers. As Handelman perceptively points out:

The stronger the shaman's ties with the spirit world became, the more capable he became of using his power to comprehend the knowledge contained in the spirit world. Then, with increased knowledge, the shaman could improve his efficacy in healing and therefore accomplish even greater good. If he continued to accomplish a greater extent of good through healing, his power continued to increase, and therefore so did his capacity to obtain further knowledge. This spiral of accomplishment was, however, always predicated on the shaman's ability to meet his ritual and interpersonal obligations, to remain pure in soul, and therefore honest, discreet, and faithful to the compact [with his spirithelpers]. (1972: 95)

While Siikala concentrates on the form, the rite, she totally ignores the content, which is the power. The most important part of the shamanic ritual is not observable if the observer does not share the awareness of the shaman. There are two levels of action and interaction operating in the shamanic rite, the ordinary reality level and the non-ordinary reality level. If the observer consistently acts as if one of the levels does not exist, then a comprehensive understanding of the rite cannot be reached. 
Siikala is absolutely correct in her statement that "The most important of the shaman's roles [and here she refers to the shaman's roles in society, not his roles in the shamanic séance] and one common to all branches of shamanism, is, however, that of the healer" (1978: 320), but she totally ignores the results of these healing séances. This, of course, could be due to the fact that in many cases the investigators whose case studies she used did not note the results. However, the missing information forms no part of her working hypothesis or theoretical framework and seems of little concern. If healing is the reason behind most shamanic rites, then it cannot be ignored in any serious analysis of the rite.

Siikala also writes:

Not even in the deepest trance does the shaman's reality-orientation completely vanish; supported by the scheme of the séance, he retains his contact with the audience. (1978: 340)

If I have understood correctly, what she means here is that the shaman is keeping at least the corner of his eye, "even in his deepest trance," on the "audience" to see if his show is having the desired effect. This is not true. What is true is that the shaman's reality orientation has changed over to the shamanic state of consciousness, which Harner points out “... involves not only a 'trance' or a transcendent state of awareness, but also a learned awareness of shamanic methods and assumptions while in such an altered state" (1980: 21. Italics added). Yes, the shaman is aware of his "audience," but his "audience" in this case are denizens of the spirit world. Moreover, to use the word audience in this case would be putting a wall between the shaman and his spirit teachers, friends, and helpers. The shaman is totally aware, but it is a shamanic awareness as he moves through non-ordinary reality.

All things considered, the concept of analysis from a role-taking point of view is extremely limiting. When applied to the work of the shaman, it gives only an in-depth description of the most superficial aspect of shamanism, adds nothing to the deeper understanding of what is really going on in the shamanic rite, and it denigrates one of the most beautiful, meaningful, and natural - yet at the same time social - human activities to be found. Of course, as Shakespeare points out, we are all actors, but we are all so much more as well. It is this something more that shamans are which makes them so worthy of study. 


\section{Intimate Participation}

An attempt to get into the shamanic séance - as an intimate participant - and get a look at or feel the shamanic ingredient was performed by the Swedish anthropologist Bo Sommarström (1989). While in Nepal, he went to a Tibetian shaman-medium to be cured for a bronchial condition which had been plaguing him for six weeks as a result of a research expedition in Tibet. Pointing out the similarities in the relationship between the shaman, his paraphernalia, and the sick person in both Tibetian and Sámi divination rites, Sommarström goes on to say that "... the differences are small and only reflect differences between settled and nomadic conditions, respectively. The main structure is essentially the same: operator, his apparatuses, and the client; and thus a general approach should be possible to the problem of 'what really happens' in the interrelationship of these three parts acting in states of trance, independent of cultural context (1989: 132. Italics added)."

Sommarström then proposes that the newer models of "reality" be applied to this problem, and briefly examines the possibilities contained in the holographic paradigm. Pointing out the limitations experienced in many branches of science from physics to psychology in working with the analytical (or digital model), he points out that "quantum physics has now taught us about the interior connection between all processes and all phenomena" (1989: 135). How similar this is to the archaic shamanic wisdom that all things are connected! As psychological-anthropologist Joan Halifax puts it:

In shamanism [the notion of interdependence] is the idea of the kinship of all life, the recognition that nothing can exist in and of itself without being in relationship to other things, and therefore that it is insane for us to consider ourselves as essentially unrelated parts of the whole Earth. (1987: 220)

Sommarström then goes on to suggest that if one accepts the many-world interpretation contained in the holographic paradigm it could shed light on what is really going on in the shamanic séance. He writes:

This 'many worlds' model resembles, appearently, basic features in traditional shamanic systems, most of which have a Universe consisting of Upper, Middle, and Lower Worlds, and sometimes sub-realms. (Sommarström 1989: 135)

To my understanding, Sommarström is making in his paper a very well argued and historic statement of the reality of non-ordinary reality. $\mathrm{He}$ closes by asking, "Is it then possible to transcend ordinary laws of 'reality,' 
especially time and space? Is this still only a matter of religious faith, philosophical classification, etc., or could this kind of phenomena be studied experientially within the frame of the new cross-scientific conceptual frames?" (1989: 136).

The answer, of course, is yes. These phenomena can be studied experientially and empirically, and no, this is not only a matter of philosophical classification or religious faith. In fact, shamanic work has never been a matter of religious faith, or as Hoppál (1987: 95) suggests, a system of beliefs. The work of the shaman has always been a matter of experience, experience which outside observers could not accept as being "real" because of their own limited understanding of reality, and so they labeled it as religious faith, imagination, beliefs, superstitions, insanity, or even play-acting.

\section{Personal Experience and Explanation}

Like many"people, in my younger days I had several powerful experiences which I could not explain, and, growing up in our culture, I had no idea how to use these experiences, or even that they could be used. Then, in my early thirties, I did have an experience of non-ordinary reality where the veil which had been covering my eyes all of my life was removed. I was able to see. The Sun stood still in the sky, and the Earth stopped. I was there, the Spirits were there, and that was how it was, and that was how it should be. It was all perfectly normal. And it was all real, absolutely real.

To say that I was confused after this experience would be an understatement, but one thing was for sure: I had been to the World of the Spirits, and I had returned. I knew that it existed, and, most important, that knowledge and awareness have never left me.

Some time later, I recognized this as an initiatory experience. It was undisciplined, but that is to be expected in the beginning of anything. The first step is meeting the spirits. Later, one learns how to talk with them, how to work with them. These lessons are taught by an ordinary reality teacher. After these have been learned come the real lessons in shamanism - from the teachers in non-ordinary reality (cf. Handelman 1967a; Handelman 1967b).

I renewed my friendship with anthropologist Michael Harner, whom I had known well in New York. Best known today for his work with applied, 
practical shamanism, the principles he works with he refers to as "core shamanism" (Harner 1980), in that they are not based on any one culture's use of shamanism, but rather on that central core of classic shamanic practices which are, or have been, found all over the world. Examples of this are sonic driving as an aid for the journey to the middle, lower, and upper worlds of non-ordinary reality, association with spirit teachers and helpers, and the treatment of illness by the removal of harmful intrusions and/or the restoration of spirit power.

In our work together over the years it has become abundently clear that the ability to shamanize is something which all humans are born with (Harner and Doore 1987; Horwitz 1989), but which our civilization's process of socialization does its best to submerge, if not strangle. It has also become absolutely clear that the use of drugs is definitely not necessary when one wishes to change the state of one's consciousness. To enter the shamanic state of consciousness, the use of singing, dancing, and drumming works as well today with modern people as it did thousands of years ago with our paleolithic ancestors.

For several years now I have been working with shamanism on a disciplined, personal level, both to seek help in my own transformation, and also to help others with their physical, spiritual, emotional, and practical issues and problems. To do this, I use shamanic rites which have been taught to me by my teachers in both realities, and in order to illustrate some of the points made in this paper I will use some of my own experiences and observations.

From the point of view of an outside observer who knew about shamanism but was not in a shamanic state of consciousness, it could seem that one of these rites could be divided into several parts, according to my appearant actions, for example, 1) preparation, 2) calling the Spirits, 3) diagnosis, 4) extraction of misplaced Spirit intrusions, 5) the shamanic journey, 6) the return of lost Spirit power, 7) the giving of thanks.

In fact, that which goes on in non-ordinary reality does have some relationship to what appears to be going on, but the setting is entirely different, to say nothing of the people present. Already in the preparatory phase, as I clean my paraphernalia in smoke, my state of consciousness starts to change, I become aware of the nearness or presence of some of my spirit-helpers, and my awareness of the ordinary reality participants of the séance starts to fade. Sometimes my helpers have advice for me when they come, and when I call to the spirits of the Earth, sometimes a hole opens for me and I can see directly down to where my teacher in the lower world lives. For the observer, it would seem that I was shaking 
my rattle at the ground in a dimly lit room. What is really going on is that I'm looking down on my Teacher's home from an altitude of about twenty meters, and she's looking up at me and it's a beautiful sunlit day, or maybe it's a rainy evening. Already at this point she often gives me very important instructions on how to go about treating the person I am working with, for example what is causing the problem, what can be done about it, and which ones among my helpers I should go to for assistance.

When it comes to the diagnosis, it may seem that I'm passing my left hand back and forth over the person I'm working on, while I shake my rattle with the right hand. Indeed, this is also happening in non-ordinary reality, because at this point I have one foot in each reality, as it were. What is also happening is that at least one of my helpers is by my side, or maybe sitting on the other side of the patient, and we're talking about what I'm finding or not finding, and what to do about it. The possibilities are almost endless. The main thing is that even though $I$ do have one foot in each reality, the part of me that is in ordinary reality is occupied with the very mundane aspects of the work, for example, moving the client's hand from his stomach so that it's possible to get ahold of the giant leech under his navel.

At some point during the rite I often make a journey to the upper or lower world on the person's behalf, either for information or lost spirit power, or both. As these journeys are very similar to the myriad journeys reported in the literature, it is not necessary to include one here (for journeys experienced by people involved in the revival of shamanism, see Harner 1980; Horwitz 1989; Ingerman 1991). However, the point at which I make the journey is not off-handedly decided, but is a decision arrived at together with my helpers. During this key part of the rite itself I may have a month's experiences within half an hour, as a journey into non-ordinary reality is a journey outside the limitations of time as we ordinarily experience it. Those participating in the ritual are generally aware of the power which comes as a result of the journey, and in some cases even witness some of the events which I experience. But to the detached observer I'm just lying on the floor, with an assistant drumming.

\section{Epilogue}

One of my teachers in this reality, Pahponee, a Kickapoo medicine woman and shaman, once told that her Grandmother, in the spirit world, told her, "You know these rituals are only needed when humans have lost their 
understanding of the greatest ceremony - Life itself. These things you already know. The greatest ceremony you can do is to live each day in a sacred way. Then you will be well off and so will those around you."

As we all also know, it has not been possible for most humans to live according to this seemingly simple advice. To make up for this loss, we have the other rituals, among them, the shamanic rituals. The purpose of this paper has been to show by expressing the shamanic point of view that most of the previously practiced methods of investigating the shamanic rite have only shown half the picture. The examination of the form of the rite is only a part. For a deeper understanding, it is also necessary to examine the rite's content. Taking the shaman's point of view into consideration, listening to how the shaman describes his experiences, and honoring that description as valid, is the first step. But to understand the content, - that is, the spirit power - it is necessary to go into the form. To do so is surprisingly easy, if one wants to. It is just a matter of becoming accessible to that power.

\section{References Cited}

\section{Eliade, Mircea}

1964 Shamanism. Archaic Techniques of Ecstacy. Princeton: Princeton University Press.

Halifax, Joan

1987 Shamanism, Mind, and No Self. In Shirley Nicholson (comp.), Shamanism. An Expanded View of Reality; pp. 213-222. Wheaton, Ill: The Theosophical Publishing House.

Handelman, Don

1967a The Development of a Washo Shaman. Ethnology 6: 444-464.

1967b Transcultural Shamanic Healing: A Washo Example. Ethnos 32: 149-166.

1972 Aspects of the Moral Compact of a Washo Shaman. Anthropological Quarterly 45: 84-101,

Harner, Michael

1980 The Way of the Shaman: A Guide to Power and Healing. New York: Harper and Row.

Harner, Michael, and Gary Doore

1987 The Ancient Wisdom in Shamanic Cultures. In: Shirley Nicholson (comp.), Shamanism. An Expanded View of Reality; pp. 3-16. Wheaton, Ill: The Theosophical Publishing House.

Honko, Lauri

1964 Role-taking of the Shaman. Temenos 4: 26-55.

Hoppál, Mihály

1987 Shamanism: An Archaic and/or Recent Belief System. In: Shirley Nicholson (comp.), Shamanism. An Expanded View of Reality; pp. 76-100. Wheaton, Ill: The Theosophical Publishing House. 


\section{Horwitz, Jonathan}

1989 On Experiential Shamanic Journeying. In: Mihály Hoppál and Otto von Sadovszky (eds.), Shamanism: Past and Present; vol. 2; pp. 373-376. Budapest: Hungarian Academy of Science. Ethnographic Institute. (ISTOR Books, 2)

Ingerman, Sandra

1991 Soul Retrieval: Mending the Fragmented Self. San Francisco: Harper and Collins. Lopatin, Ivan A.

1940-41 A Shamanistic Performance to Regain the Favor of the Spirit. Anthropos 35/36: 352-355.

Moody, Raymond A. Jr.

1977 Reflections on Life after Life. New York: Bantam.

Siikala, An na-Leena

1978 The Rite Technique of the Siberian Shaman. Helsinki: Academia Scientiarum Fennica. (FF Communications, 220)

Sommarström, Bo

1989 The Sami Shaman's Drum and the Holographic Paradigm Discussion. In: Mihály Hoppál and Otto von Sadovszky (eds.), Shamanism: Past and Present; vol. 1; pp. 125-144. Budapest: Humgarian Academy of Science. Ethnographic Institute. (ISTOR Books, 1)

Wasson, R. Gordon et al.

1974 Maria Sabina and her Mazatec Velada. New York: Harcourt Brace Jovanovich. 